\title{
Electrocardiography during Manual Dilatation of the Anus
}

\author{
R. E. C. COLLINS, R. H. FELL, P. H. LORD
}

current illness. No premedication was given. Their permission having been obtained, the patients were connected to the E.C.G. and asked to lie in the left lateral position. The standard limb lead giving the largest deflection was chosen for the recording. Summary

Manual dilatation of the anus was carried out on 50 unpremedicated outpatients under propanidid, nitrous oxide, and halothane anaesthesia with E.C.G.monitoring. About half of the patients received intravenous atropine with the propanidid. The operation induced a variety of changes in heart rate but in the whole experiment only two isolated cardiac arrhythmic complexes were seen-a single defect of conduction and a solitary ventricular extrasystole. Changes in rate were not modified by atropine. It is concluded that manual dilatation of the anus is a safe procedure when carried out under the anaesthetic described and that prior medication with atropine is not necessary. This work supports the view that propanidid protects patients from most abnormalities of heart action which result from intense visceral stimulation.

\section{Introduction}

One of the dangers of stimulating the anus and rectum is that of reflex cardiac standstill (British Medical fournal, 1969). Fletcher et al. (1968) reported three deaths in a series of 1,800 sigmoidoscopies carried out without anaesthesia. They went on to show that in 100 patients on whom sigmoidoscopy was carried out under E.C.G. monitoring the incidence of abnormal rhythms was $17 \%$ in patients with normal hearts and $40 \%$ in those who had cardiac abnormalities. Clearly stretching the anus to admit between four and eight fingers is much more stimulating than sigmoidoscopy, and general anaesthesia does not protect patients from reflex cardiac effects (Lee, 1958); indeed, halothane is known to increase the likelihood of irregularities in the presence of circulating adrenaline (Millar et al., 1958). In the past six years at Wycombe General Hospital, however, about 1,500 patients have been treated by Lord's procedure (Lord, 1968; Lord, 1969), usually under anaesthesia with propanidid, nitrous oxide, and halothane, and though this number is comparable with that in the series quoted above none died or experienced any major cardiac complication.

We decided to investigate the E.C.G. changes which accompanied manual dilatation of the anus under the above anaesthetic sequence and to test the effect of atropine on the incidence of such changes.

\section{Method}

Between September 1971 and March 197261 unselected patients with haemorrhoids were admitted to the day-stay ward having had nothing to eat or drink for eight hours. A medical history was taken and each patient was examined to exclude

Wycombe General Hospital, High Wycombe, Bucks

R. E. C. COLLINS, M.B., F.R.C.s., Surgical Registrar (Present address: Department of Surgery, Guy's Hospital, London SEI 9RT)

P. H. LORD, M.CHIR., F.R.C.s., Consultant Surgeon

Windsor Group of Hospitals

R. H. FELL, M.B., F.F.A.R.C.S., Consultant Anaesthetist Anaesthesia was induced with propanidid $(7.0 \mathrm{mg} / \mathrm{kg}$ intravenously), and this was followed by atropine sulphate $(0.6 \mathrm{mg})$ if the patient's birthday fell on an even day of the month. Each patient then inhaled $30 \%$ oxygen in nitrous oxide and $2 \%$ halothane for five minutes. The procedure of manual dilatation of the anus was carried out as described by Lord (Lord, 1968; Lord, 1969).

The E.C.G. was recorded during the induction of anaesthesia, while the perineum was being inspected, and during the sigmoidoscopy. Recording was continued during the more stimulating anal stretch and insertion of the haemostatic sponge. Electrical and mechanical interference led to the rejection of 11 tracings, so that 50 successful graphs remained; of these 26 related to patients who had received atropine. The satisfactory traces were scrutinized to determine the incidence of abnormal complexes during all parts of the procedure and to deduce the heart rates immediately before and immediately after both the anal stretch and the insertion of the haemostatic sponge.

\section{Results}

After the administration of propanidid the pulse rate was invariably higher than the accepted normal value and was higher still in those who received atropine. Inspection of the perineum, rectal examination, proctoscopy, and sigmoidoscopy produced little change in pulse rate and no abnormal beats were found.

\section{ARRHYTHMIAS}

During the whole experiment only two abnormal electrical complexes were seen. One patient who had received atropine (case 8) showed a single conduction defect (fig. 1) in response to manual dilatation, while another (case 32) who had not received atropine developed a single ventricular extrasystole (fig. 2) several seconds after the insertion of the sponge.

\section{Changes in Rate}

The changes in heart rate resulting from the two most stimulating parts of the procedure are shown in the table. The mean of the heart rates in the group who received atropine was 122 beats/min before manual dilatation and 121 beats/min afterwards. Both before and after the insertion of the sponge the mean rate was 128 beats $/ \mathrm{min}$. This change is not significant.

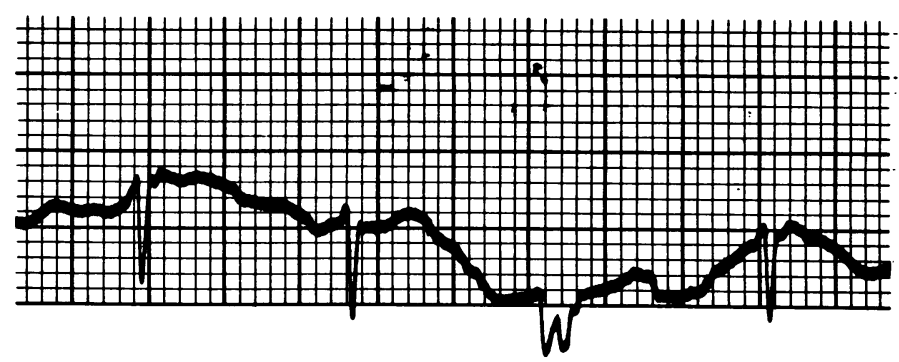

FIG. 1-Case 8. E.C.G. showing single conduction defect. 


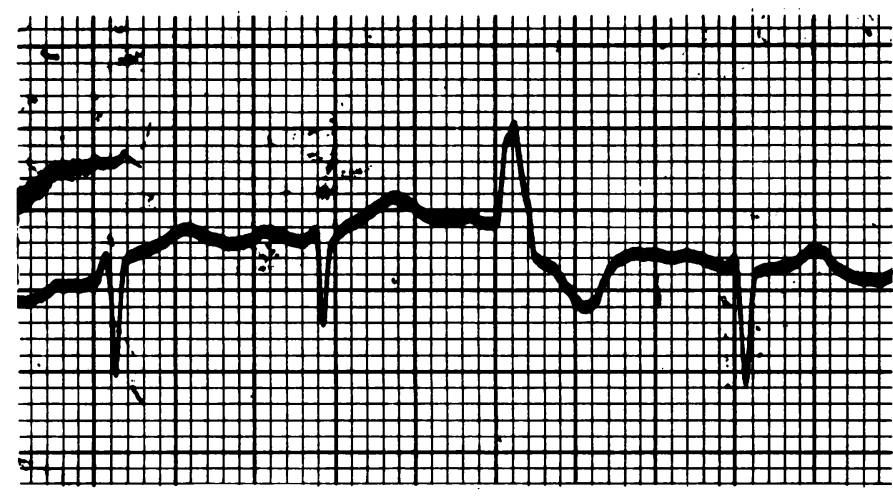

FIG. 2-Case 32. E.C.G. showing single ventricular extrasystole.

The individual changes showed six falls and seven rises in pulse rate after the first stimulus and five falls and six rises in response to the second; only one of these changes (case 23) was of more than $10 \%$.

The mean heart rates before and after each stimulus in those who did not receive atropine was 107 beats/min before and 108 beats/min after manual dilatation respectively, and 114 beats/ min both before and after the insertion of the sponge. In this group there were nine falls and 10 rises in pulse rate with the first stimulus and two falls and five rises in response to the second. In contrast to the first group seven of these changes were greater than $10 \%$, though no change was so dramatic as to give cause for concern.

In both groups the mean pulse rate before insertion of the sponge was greater than it had been before dilatation, but this change was not sufficiently consistent to be statistically significant $(P>0.05)$.

\section{Discussion}

The essence of any operative procedure is that it should be safe and effective. The efficacy of this procedure has been described elsewhere (Lord, 1968; MacIntyre and Balfour, 1972). The work presented here confirms that manual dilatation of the anus can be carried out safely, even on an outpatient basis. The cardiac complications expected on theoretical grounds do not seem to be an important factor.
Propanidid has been shown to have a quinidine-like effect (Johnstone and Barron, 1968; Bernhoff et al., 1972), but there is a difference of opinion on whether it prevents ventricular arrhythmias. Boulton and Rushman (1971), presenting their own work and invoking the results of others, are satisfied that ventricular arrhythmias are much less common after propanidid than after barbiturates. On the other hand, Mann et al. (1971), using smaller doses, found no significant difference between the effects of the two drugs on the heart. Our findings suggest that propanidid not only protects the heart from most reflex arrhythmias but may also prevent those produced by halothane and nitrous oxide. It is widely believed that slowing of the heart on visceral stimulation is mediated by the vagus nerve, but we were surprised to find that there were no dramatic falls in pulse rate in either group; it may be that the tachycardia which occurs after the administration of propanidid accounts for this observation. A common prelude to day-stay surgery is the administration of atropine as a premedication. This may produce symptoms such as a thumping heartbeat, dryness of the mouth, foul breath, and blurred vision. This work suggests that premedication with atropine is not necessary for the procedure. The difference between our control and test groups was not significant with respect to heart rate and arrhythmias. Furthermore, since the procedure is carried out with the patient in the left lateral position saliva is unlikely to irritate the larynx and cause laryngeal spasm.

Where pain relief is concerned the recovery from propanidid is sufficiently rapid to allow the administration of intramuscular analgesics soon after the procedure so that the haemostatic sponge may be removed without excessive pain.

The results of this trial have been most gratifying, but other workers have reported an occasional anaphylactoid response to the administration of propanidid (Johns, 1970; Lavard, 1970). This may be caused by Cremophor EL, which holds the propanidid in solution and is known to cause histamine release in dogs (Wirth and Hoffmeister, 1968) and in rats (Wirth and Hoffmeister, 1965) but does not cause bronchospasm in guineapigs. Furthermore, reports of similar anaphylactoid responses have begun to come in since the release of the steroid intravenous anaesthetic Althesin, which is also held in solution by Cremophor EL (Glaxo Laboratories, personal communication). The characteristics of this anaphylactoid response in man are a red face, hypotension, and a thready pulse. In the event of this rare occurrence the patient should be tilted head down and given oxygen, steroids, fluids, adrenergic drugs, antihistamines, and calcium chloride.

\begin{tabular}{|c|c|c|c|c|c|c|c|c|c|}
\hline \multicolumn{5}{|c|}{ After Atropine } & \multicolumn{5}{|c|}{ Without Atropine } \\
\hline Case No. & $\begin{array}{c}\text { Before } \\
\text { Diln. } \\
\end{array}$ & $\begin{array}{l}\text { After } \\
\text { Diln. }\end{array}$ & $\begin{array}{r}\text { Before } \\
\text { Sponge } \\
\end{array}$ & $\begin{array}{c}\text { After } \\
\text { Sponge }\end{array}$ & Case No. & $\begin{array}{c}\text { Before } \\
\text { Diln. } \\
\end{array}$ & $\begin{array}{l}\text { After } \\
\text { Diln. } \\
\end{array}$ & $\begin{array}{l}\text { Before } \\
\text { Sponge }\end{array}$ & $\begin{array}{l}\text { After } \\
\text { Sponge }\end{array}$ \\
\hline $\begin{array}{r}1 \\
2 \\
3 \\
4 \\
5 \\
6 \\
7 \\
8 \\
9 \\
10 \\
11 \\
12 \\
13 \\
14 \\
15 \\
16 \\
17 \\
18 \\
19 \\
20 \\
21 \\
22 \\
23 \\
24 \\
25 \\
26\end{array}$ & $\begin{array}{l}107 \\
115 \\
107 \\
130 \\
130 \\
150 \\
128 \\
107 \\
100 \\
97 \\
150 \\
125 \\
94 \\
130 \\
143 \\
1136 \\
136 \\
107 \\
143 \\
115 \\
110 \\
75 \\
113 \\
145 \\
\end{array}$ & $\begin{array}{l}110 \\
110 \\
107 \\
120 \\
130 \\
150 \\
128 \\
110 \\
104 \\
100 \\
150 \\
120 \\
88 \\
130 \\
143 \\
155 \\
136 \\
136 \\
110 \\
113 \\
110 \\
1105 \\
115 \\
150 \\
\end{array}$ & $\begin{array}{l}115 \\
115 \\
105 \\
120 \\
130 \\
155 \\
130 \\
120 \\
120 \\
110 \\
125 \\
128 \\
155 \\
150 \\
155 \\
136 \\
150 \\
143 \\
110 \\
150 \\
125 \\
143 \\
\end{array}$ & $\begin{array}{l}122 \\
115 \\
105 \\
120 \\
135 \\
155 \\
130 \\
120 \\
130 \\
110 \\
125 \\
128 \\
155 \\
150 \\
150 \\
136 \\
155 \\
140 \\
115 \\
145 \\
81 \\
136 \\
136\end{array}$ & $\begin{array}{l}27 \\
28 \\
29 \\
30 \\
31 \\
32 \\
33 \\
34 \\
35 \\
36 \\
37 \\
38 \\
39 \\
40 \\
41 \\
42 \\
43 \\
44 \\
45 \\
46 \\
47 \\
48 \\
49 \\
50\end{array}$ & $\begin{array}{r}107 \\
85 \\
103 \\
97 \\
107 \\
97 \\
94 \\
103 \\
125 \\
155 \\
125 \\
125 \\
85 \\
103 \\
110 \\
136 \\
107 \\
125 \\
130 \\
98 \\
85 \\
110 \\
71 \\
85\end{array}$ & $\begin{array}{r}107 \\
100 \\
100 \\
100 \\
100 \\
97 \\
92 \\
107 \\
125 \\
130 \\
103 \\
125 \\
88 \\
107 \\
115 \\
128 \\
100 \\
122 \\
143 \\
143 \\
81 \\
112 \\
85 \\
85\end{array}$ & $\begin{array}{r}115 \\
115 \\
97 \\
103 \\
100 \\
120 \\
103 \\
110 \\
125 \\
125 \\
125 \\
103 \\
103 \\
130 \\
120 \\
150 \\
125 \\
120 \\
94 \\
83\end{array}$ & $\begin{array}{l}120 \\
115 \\
97 \\
103 \\
100 \\
120 \\
110 \\
110 \\
130 \\
125 \\
125 \\
103 \\
133 \\
133 \\
120 \\
1161 \\
115 \\
1154 \\
83\end{array}$ \\
\hline Mean $( \pm$ S.D. $)$ & $122(20)$ & $121(20)$ & $128(20)$ & $128(20)$ & Mean ( \pm S.D. $)$ & $107(19)$ & $108(17)$ & $114(15)$ & $114(17)$ \\
\hline
\end{tabular}


We should like to thank the nursing staff of the recovery and theatre suites at Wycombe General Hospital, and Miss J. Spearpoint and Mrs. A. Andrews for secretarial help.

\section{References}

Bernhoff, A., Eklund, B., and Kaijser, L. (1972). British fournal of Anaes-

thesia, 44, 2.
Boulton, T. B., and Rushman, G. B. (1971). Epontol Symposium, Scheveningen (12 June). British Medical fournal, 1969, 4, 319

Fletcher, C. F., Earnest, D. L., Shuford, W. F., and Wenger, N. K. (1968). Archives of Internal Medicine, 122, 483.
Johns, G. (1970). British fournal of Anaesthesia, 42, 74.

Johnstone, M., and Barron, P. T. (1968). Anaesthesia, 23, 180.

Lavard, D. G.' (1970). British fournal of Anaesthesia, 42, 652.

Lee, J. A. (1958). Synopsis of Anaesthesia, chapt. 9, p. 227. Bristol, John Wright.

Lord, P. H. (1968). Proceedings of the Royal Society of Medicine, 61, 935.

Lord, P. H. (1969). British fournal of Surgery, 56, 747.

MacIntyre, I. M. C., and Balfour, T. W. (1972). Lancet, 1, 1094.

Mann, P. E., et al. (1971). Anaesthesia, 26, 3.

Millar, R. A., Gilbert, R. G. B., and Brindle, G. F. (1958). Anaesthesia, 13, 164.

Wirth, W., and Hoffmeister, F. (1965). In Die intravenose Kurznarkose mit dem neuen Phenoxyessigsaurederivativ Propanidid (Epontol), ed. K. Horatz, R. Frey, and M. Zindler, p. 17. Heidelberg, Springer.

Wirth, W., and Hoffmeister, F. (1968). Folha Médica, 57, 179.

\section{PRELIMINARY COMMUNICATION}

\section{Auditory Perception}

\section{J. A. M. MARTIN, DOROTHY MARTIN}

British Medical fournal, 1973, 2, 459-461

\begin{abstract}
Summary
Auditory perceptual tasks involving the discrimination of fine differences in frequency, duration, or rhythmic pattern were given to a group of sixth form schoolboys. The results indicate that there is a wide range of auditory skills for different individuals, even within a relatively homogeneous group. There are also differences in a person's ability to carry out distinct tasks; there does not necessarily appear to be any correlation between his ability for each task.

The findings support observations arising out of consideration of hearing problems in children and adults that pure tone threshold audiometry and its derivatives give an inadequate definition of hearing disorder and a limited understanding of the nature of hearing.
\end{abstract}

\section{Introduction}

Hearing is measured clinically by pure tone audiometry, a procedure which determines the threshold of sensation for a number of frequencies between $125 \mathrm{~Hz}$ and $8 \mathrm{kHz}$. Consequently, deafness tends to be equated with hearing loss, and defined in terms of the physical features of frequency and intensity. The theoretical background derives largely from Fourier's mathematical analysis of irregular wave forms. He showed that these could be resolved into a number of constituent sine waves, the acoustical equivalent of which is pure tones. Pure tone threshold audiometry with its various refinements is now a highly developed tool which has gained universal acceptance in the estimation of hearing loss and for the diagnostic siting of the lesion in the middle ear, cochlea, or auditory nerve.

The constraints of the test procedure disguise limitations in our ability to investigate hearing function, and Littler (1960) was impelled to ask why such importance was attached to pure tone analysis. From a number of objections which might be levelled at the technique, the most important is that it gives no

Royal National Throat, Nose, and Ear Hospital, London W.C.1 J. A. M. MARTIN, F.R.C.S., D.L.O., Director, Nuffield Hearing and Speech

DOROTHY MARTIN, s.R.N., Research Assistant measure of the patient's ability to distinguish between sounds. It is possible for the clinician to answer the question "How much sound is heard?", but not "How are sounds being heard?"

The investigation of hearing in young children produces a number of problems which would otherwise be unsuspected if they could be coerced into the formal situation required by pure tone audiometry. This may be exemplified by certain children who are slow in learning to talk. Their difficulty seems to consist not so much of an alteration of auditory threshold but of an impaired ability to sort out, or make sense of, acoustical events. Consideration of a number of developmental and abnormal responses leads one to suggest that there are factors on the sensory side, in addition to simple hearing loss, which must be studied if there is to be an adequate explanation of the differing patterns of hearing behaviour (Martin, 1971).

Neurological disorder in the adult affirms the possibility that a person may have difficulty in recognizing meaningful sounds yet have no hearing loss. In such patients Bay (1964) questions the value of pure tone threshold audiometry and concludes that there is no non-verbal (our italics) test which is sufficiently sensitive to show disorders of auditory perception.

\section{Levels of Hearing}

There is sufficient evidence to justify reappraisal of presentday concepts of hearing and of deafness, and of the methods adopted to investigate them. Hearing may be regarded as an activity taking place at three levels of organization.

(1) The transformation of acoustic energy occurring in the air about our ears into activity within the auditory nerves, with intermediate transformations occurring in the middle ear and cochlea. This is the primary sensory process, investigation of which has given rise to an impressive amount of experimental work and to a number of theories of hearing. Pure tone audiometry measures dysfunction only at this level.

(2) The ability to discriminate between sounds. Sounds entering the auditory space in which we are immersed are never steady state pure tones, but are acoustically complex, having form, structure, and movement. They start and stop, abruptly or gradually, and last for a greater or lesser period of time. They may be rapidly repetitive, they may be periodic or random, their frequency characteristics and loudness levels may alter. They may come from one direction or another or move through space, they may be many or few. We can sort out this multiplicity of acoustical events arising from activity in the world around. A theory of hearing needs not only to explain the activity of the end organ, but how the central nervous system processes the sensory input flowing into it from the auditory nerves. There is no reason to suppose that this processing is confined to the area labelled "auditory cortex." The remarkable complexity of the auditory pathways in the brain stem, mid-brain, and thalamic 